\title{
Conformationally Driven Gas-Phase H/D Exchange of Dinucleotide Negative Ions
}

\author{
Dorothée Balbeur, ${ }^{\mathrm{a}}$ Dominique Dehareng, ${ }^{\mathrm{b}}$ and Edwin De Pauw ${ }^{\mathrm{a}}$ \\ a Laboratory of Mass Spectrometry, University of Liège, Liège, Belgium \\ ${ }^{\mathrm{b}}$ Center for Protein Engineering, University of Liège, Liège, Belgium
}

Gas-phase hydrogen/deuterium exchange of six deprotonated dinucleotides with $\mathrm{CD}_{3} \mathrm{OD}$ was performed in the second hexapole of a Fourier transform ion-cyclotron resonance (FTICR) mass spectrometer. To complete these experiments, dynamic simulations were carried out to investigate the different conformations adopted by the dinucleotides. In the experimental conditions and in integrating the experimental and theoretical results, H/D exchange was shown to be controlled by hydrogen accessibility and not by the chemical nature of the heteroatom bearing the exchangeable hydrogen. A model including simultaneous H/D exchanges at the experimental time scale was used to reproduce the dinucleotide H/D exchange kinetic plots. The relay mechanism was not relevant for dinucleotides. This allowed the H/D exchange rates to be directly linked to conformations. (J Am Soc Mass Spectrom 2007, 18, 1827-1834) (c) 2007 American Society for Mass Spectrometry

$\mathrm{T}$ The conformations of biomolecules depend on intramolecular noncovalent interactions. These interactions determine, at a molecular level, a vast majority of biological processes (molecular recognition, regulation, transport, etc.) that define the function of the biomolecule. Hydrogen/deuterium (H/D) exchange combined with mass spectrometry is an efficient tool for studying the gas-phase structure of biomolecules [1-16]. The rate of gas-phase H/D exchange has been shown to be a function of the reagent used for exchange, the concentration of this reagent, the charge states of the biomolecule, the gas-phase basicity/acidity of exchangeable sites, and of the internal structure of the biomolecular ions [1-16]. So the determination of the exchanged hydrogen number and of the H/D exchange kinetics allows structural isomers of the biomolecule to be distinguished, and structural and thermochemical features to be deduced. H/D exchange reactions have been performed using a Fourier transform ion-cyclotron resonance (FTICR) mass spectrometer [1-11] or a quadrupole ion trap [10-16]. Though these two instruments show several differences, they allow the ions to be trapped for variable periods of time in the presence of the deuterating reagent held at a constant pressure.

Deoxyribose monophosphate nucleotides are the structural units of DNA. The gas-phase H/D exchange of these units have been carried out in positive $[7,8]$ or in negative $[3-5,8]$ ion mode with an FTICR-MS and, more recently, in negative ion mode with a quadrupole ion trap [16]. These different studies have shown that

Address reprint requests to Dr. D. Balbeur, Laboratory of Mass Spectrometry, University of Liège, 3 Allée de la Chimie Bat. B6c, B-4000 Liège, Belgium. E-mail: dbalbeur@ulg.ac.be the extents and rates of exchange depend on the nucleobase (identity, orientation, and gas-phase acidity of the exchangeable hydrogen) and on the position $\left(3^{\prime}\right.$ or $\left.5^{\prime}\right)$ and flexibility of the terminal phosphate group. They have also concluded that the most probable mechanism of exchange is the relay mechanism. This mechanism requires the formation of a hydrogenbonded complex between a hydrogen donor site of the nucleotide, the deuterating reagent, and a deuterium acceptor site (the phosphate group) of the nucleotide, the deuterating reagent bridging the two sites of the nucleotide.

The present work focuses on the examination of the gas-phase H/D exchange behavior of six deprotonated dinucleotides. The gas-phase conformations of dinucleotides have already been investigated by molecular modeling calculations and ion mobility experiments [17]. The dinucleotides adopt distinctive conformations that interconvert at the experimental time scale of an FTICR-MS. To determine the lifetime of the distinctive structures, experimental conditions (the type and pressure of the exchange gas) were chosen such that the $\mathrm{H} / \mathrm{D}$ exchange reaction was not the limiting step. The data presented here underline the importance of hydrogen accessibility to explain the rates of hydrogen exchange. The accessibility of the exchangeable hydrogen is controlled not only by the distinctive structures adopted by the dinucleotide but also by the protection extent of the hydrogen in these structures, which is linked to the mean time spent in the various isomeric structures. The relay mechanism is not relevant for dinucleotides as the distances between the hydrogen donor and deuterium acceptor sites are not compatible. 


\section{Experimental}

\section{Sample Preparation}

The six dinucleotides (dTT, dAT, dAA, dTG, dAG, and dGG) were obtained from Eurogentec (Seraing, Belgium). $\mathrm{CD}_{3} \mathrm{OD}$ was purchased from Euriso-Top (Gif sur Yvette, France). All of these compounds were used without further purification. Stock solutions of the dinucleotides $\left(400 \times 10^{-6} \mathrm{M}\right)$ were prepared in water. Working solutions $\left(1.1765 \times 10^{-5} \mathrm{M}\right)$ were obtained by dilution in water. The injection solutions were prepared by adding the appropriate amount of $\mathrm{MeOH}$ to obtain a $\mathrm{MeOH} / \mathrm{H}_{2} \mathrm{O}$ ratio of $15 / 85$ (vol/vol) and a dinucleotide concentration of $10^{-5} \mathrm{M}$.

\section{Mass Spectrometry}

Experiments were performed with a 9.4 tesla Apex-Qe FTICR mass spectrometer (Bruker Daltonics, Billerica, MA). The dinucleotide solutions were infused via an external Apollo electrospray ion source at a flow rate of $120 \mu \mathrm{L} / \mathrm{h}$ with the assistance of $\mathrm{N}_{2}$ nebulizing gas. The off axis sprayer was grounded, the end-plate was set to $3 \mathrm{kV}$ and the inlet capillary was set to $3.5 \mathrm{kV}$ for the generation of dinucleotide anions. $\mathrm{N}_{2}$ heated drying gas $\left(250{ }^{\circ} \mathrm{C}\right)$ was applied to assist desolvation of ESI droplets. Ions were accumulated in the first hexapole for $1.5 \mathrm{~s}$ and transferred non-mass selectively through the quadrupole into the second hexapole for $10 \mathrm{~ms}$. They were trapped for variable periods of time in this second hexapole (h2) to carry out $\mathrm{H} / \mathrm{D}$ exchange reactions, and were then transferred through high voltage ion optics and captured by static trapping in an ICR cell. All mass spectra were acquired with XMASS (version 7.0.8; Bruker Daltonics) in broadband mode from $\mathrm{m} / \mathrm{z} 350$ to 900 with $512 \mathrm{k}$ data points and summed over 5 scans. A mass list, in which $m / z$ values and peak heights are recorded, was created by DataAnalysis (version 3.4; Bruker Daltonics).

\section{H/D Exchange}

All of the H/D exchange reactions were conducted in the gas phase in the collision cell (second hexapole h2) of the 9.4 tesla Apex-Qe FTICR mass spectrometer. $\mathrm{CD}_{3} \mathrm{OD}$ was used as the deuterating agent. Due to its vapor pressure at $\sim 20^{\circ} \mathrm{C}$, it was introduced into the second hexapole through the nozzle valve usually used for the collision gas (Ar). Using this system, only $\mathrm{CD}_{3} \mathrm{OD}$ was introduced into h2 with a measured pressure in the surrounding vacuum chamber of $3.75 \times 10^{-6}$ torr, which corresponds to a pressure in the collision cell of $\sim 7.5 \times 10^{-4}$ torr. The extent of exchange was observed by monitoring the relative abundance of the precursor ion and of the deuterated species while the $\mathrm{CD}_{3} \mathrm{OD}$ pressure was held at $\sim 7.5 \times 10^{-4}$ torr. Ions were accumulated in the collision cell for $10 \mathrm{~ms}$ and were then trapped for $H / D$ exchange reactions from
$10 \mathrm{~ms}$ to $600 \mathrm{~s}$ (the ions entered the hexapole in one group and no other ions entered during the exchange time). The six dinucleotides were analyzed individually on the same day under identical conditions. The experiments were repeated on other days for the same reaction times under conditions as similar as possible to assess reproducibility.

To analyze H/D exchange spectra, an in-house software was used. This software utilizes the known isotopic distribution (percentage of each peak) of the nondeuterated ion. Moreover, it is considered that the ion with a fixed number $X$, of exchanged hydrogens has the same isotopic distribution but shifted by $X / z$ unit. The software determines, at each reaction time, the composition of each deuterated species that fits best to the experimental isotopic distribution. The plotting of these compositions to obtain the kinetic plots was done with SigmaPlot (version 9; Systat Software, Inc., San Jose, CA). Several methods for quantitation of peak magnitudes exist and are based on peak height or peak area [18]. In ${ }^{\circ}$ this ${ }^{\circ}$ work, $^{\circ}$ isotopic $^{\circ}$ distributions $^{\circ}$ were $^{\circ}$ described from relative peak heights as advised by A. G. Marshall et ${ }^{\circ}$ al. ${ }^{\circ}[19]$. Peak $^{\circ}$ area $^{\circ}$ measurements ${ }^{\circ}$ can $^{\circ}$ be $^{\circ}$ problematic because of the presence of wiggles, known as "Gibbs oscillations," in FTICR mass spectra. These oscillations result from truncation of the time-domain ICR signal at time, $t$, before it has decayed to zero.

\section{Molecular Modeling}

Dynamic simulations were carried out with HyperChem (version 7; Hypercube, Inc., Gainesville, FL) to investigate the different conformations adopted by the dinucleotides. $\mathrm{BIO}+(\mathrm{CHARMM})$ was used as the force field. Before dynamic simulations, the charges of different atoms were recalculated; atoms of the phosphate group, the first carbon and hydrogen atoms near the phosphate group, and the hydrogen atoms of $3^{\prime}$ and $5^{\prime}$ $\mathrm{OH}$ extremities. These charge recalculations were performed by single point calculation with ZINDO/1 (semi-empirical SCF method). The net atomic charges were recalculated to take into account the negative charge on the phosphate group. For each deprotonated dinucleotide, two molecular dynamics simulations of 10,000 ps at $\sim 300 \mathrm{~K}$ were done. In these simulations, snapshots were saved every 0.05 ps and distances between key atoms were monitored. The two dynamic simulations differed by molecule conditioning. For the first simulation, the deprotonated dinucleotide was heated for $100 \mathrm{ps}$ at $900 \mathrm{~K}$ and then cooled during $152 \mathrm{ps}$ from 900 to $300 \mathrm{~K}$. For the second simulation, the ion was geometrically optimized, heated during 150 ps from 0 to $300 \mathrm{~K}$, and then kept for 50 ps at $300 \mathrm{~K}$.

It ${ }^{\circ}$ has ${ }^{\circ}$ been $^{\circ}$ shown $^{\circ}$ via $^{\circ} \mathrm{REMPI}^{\circ}$ spectroscopy ${ }^{\circ}[20]^{\circ}$ and in ${ }^{\circ}$ modeling ${ }^{\circ}$ calculations $^{\circ}[6,21-23]^{\circ}$ that ${ }^{\circ}$ guanine ${ }^{\circ}$ favors a syn orientation in the gas phase. Syn and anti are terms that are associated with the orientation of the nucleobase with respect to the sugar. In the anti orientation, the six-membered pyrimidine ring in purines 
and $\mathrm{O}_{2}$ in pyrimidines are pointing away from the sugar, and in the syn orientation, it is over or toward the ${ }^{\circ}$ sugar $^{\circ}[24] .^{\circ}$ To $^{\circ}$ analyze ${ }^{\circ}$ the ${ }^{\circ}$ behavior $^{\circ}$ of $^{\circ}$ deprotonated dTG, dAG, and dGG in the previous molecular dynamics calculations, ab initio geometry optimizations $^{\circ}$ with $^{\circ}$ syn $^{\circ}$ and $^{\circ}$ anti $^{\circ}$ conformations $^{\circ}$ of $^{\circ} \mathrm{G}^{\circ}$ in $^{\circ}$ the $^{\circ} 3^{\prime}$ position ${ }^{\circ}$ were $^{\circ}$ performed $^{\circ}$ with $^{\circ}$ Gaussian $^{\circ} 03^{\circ}[25] .{ }^{\circ}$ To compare the minimized energy obtained for the two conformations syn and anti, different levels of theory and different basis sets were used; RHF/6-31G-aug,
B3LYP/6-31G-aug, RHF/6-31*G-aug; aug means that the basis set is augmented with diffuse functions on the oxygens and nitrogens and polarization functions on phosphorus. The added basis functions were each represented by one Gaussian function. They corresponded, on the one hand, to $\mathrm{s}$ and $\mathrm{p}$ diffuse functions for oxygen and nitrogen atoms (with an exponent equal to 0.0845 and 0.0639 for oxygen and nitrogen atoms, respectively) and on the other hand to $\mathrm{d}$ polarization functions for the phosphorus atom

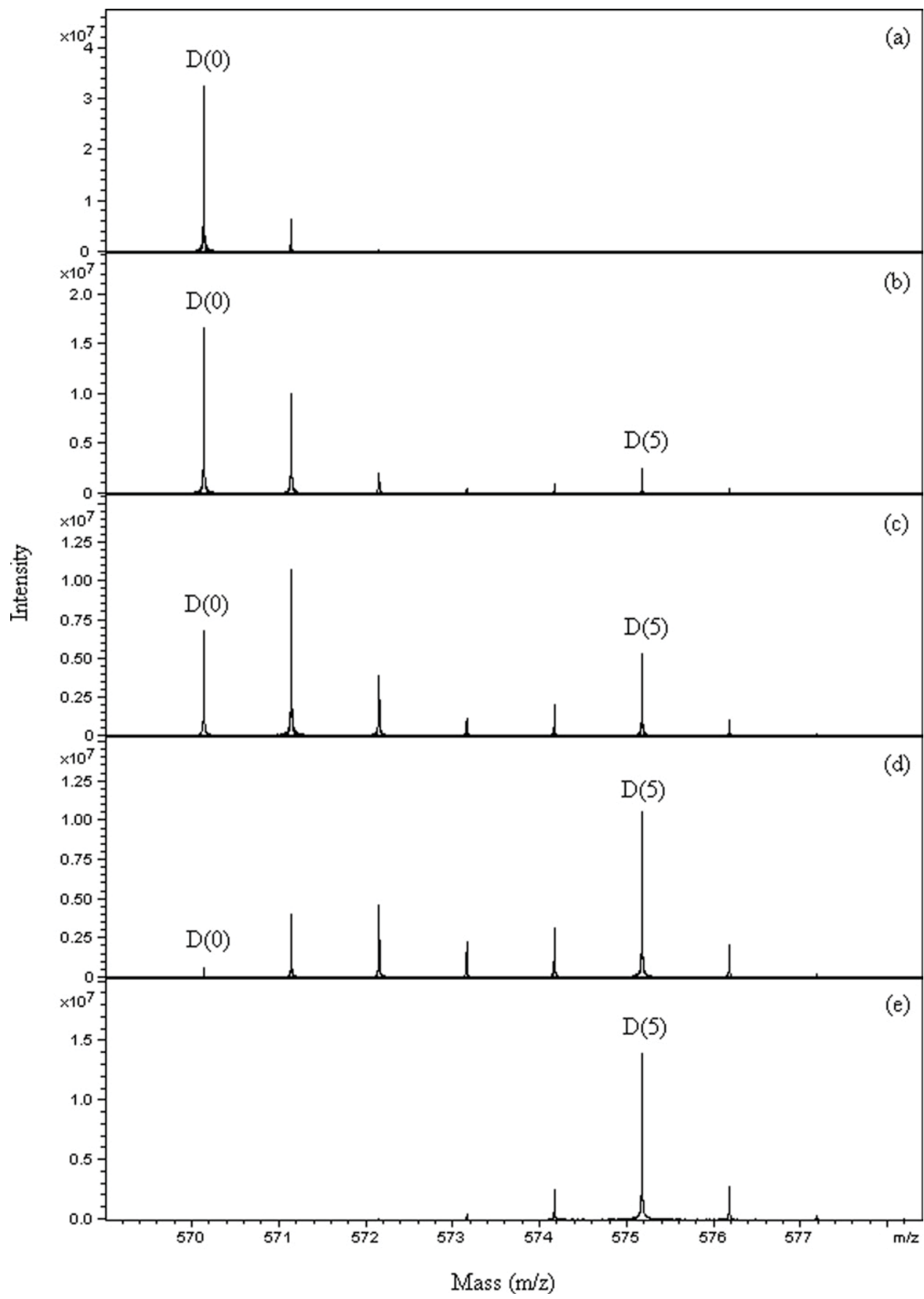

Figure 1. Representative mass spectra for the reaction of deprotonated dTG with $\mathrm{CD}_{3} \mathrm{OD}$ in the second hexapole of an FTICR-MS. H/D exchange reaction times are (a) $0 \mathrm{~s}$, (b) $30 \mathrm{~s}$, (c) $60 \mathrm{~s}$, (d) $150 \mathrm{~s}$, and (e) $600 \mathrm{~s}$. 
(with an exponent equal to 0.55). Five starting points were used for each conformation.

\section{Kinetic Simulations}

To analyze the H/D exchange kinetics, the software Matlab (version 7.3.0; The MathWorks, Inc., Natick, MA) was used. This software allows personal sets of coupled differential equations and personal sets of rate constants to be introduced. The construction of kinetic plots was done to reproduce H/D exchange experimental plots.

\section{Results and Discussion}

\section{H/D Exchange}

The typical progression of the hydrogen/deuterium exchange reactions of the deprotonated dinucleotides with $\mathrm{CD}_{3} \mathrm{OD}$ in the second hexapole of the FTICR-MS is illustrated ${ }^{\circ}$ in $^{\circ}$ the ${ }^{\circ}$ case $^{\circ}$ of $^{\circ} \mathrm{dTG}^{-\circ}$ in $^{\circ}$ Figure $^{\circ} 1 .^{\circ} \mathrm{As}^{\circ}$ the reaction time increased from 0.01 to $600 \mathrm{~s}$, the increase of exchanged hydrogen number $[\mathrm{D}(X)$ corresponds to $X$ exchanged hydrogen atoms] was observed with a corresponding decrease of the abundance of the precursor ion, $\mathrm{D}(0)$. As described previously, an in-house software was used to analyze the H/D exchange mass spectra. Kinetic plots were obtained from the calculated composition of each deuterated species at each reaction time. The kinetic plots of $\mathrm{dTT}^{-}, \mathrm{dAA}^{-}$, and $\mathrm{dTG}^{-}$are presented ${ }^{\circ}$ in $^{\circ}$ Figure $^{\circ} 2 .{ }^{\circ}$ From $^{\circ}$ the ${ }^{\circ}$ kinetic $^{\circ}$ plots, ${ }^{\circ}$ some features were underlined [the major species at given exchange times, the partial exchange, the simultaneous increase of the $\mathrm{D}(1)$ and $\mathrm{D}(2)$ species, the fast increase of species with a large number of exchanged hydrogens]. They are summarized for all of the six deprotonated dinucleotides ${ }^{\circ}$ in $^{\circ}$ Table $^{\circ} 1 .^{\circ}$ These $^{\circ}$ features ${ }^{\circ}$ could $^{\circ}$ not $^{\circ}$ be explained by only the hydrogen gas-phase acidities of $5^{\prime \circ}$ and ${ }^{\circ} 3^{\prime \circ}$ phosphate ${ }^{\circ}$ mononucleotides ${ }^{\circ}[16] .{ }^{\circ} \mathrm{So},{ }^{\circ}$ to ${ }^{\circ} \mathrm{ex}-$ plain the features, the three-dimensional gas-phase structure of the six deprotonated dinucleotides was investigated by molecular dynamics calculations.

\section{Molecular Modeling}

During molecular dynamics calculations, distances between exchangeable hydrogens and heteroatoms with which they could interact were monitored. Distinctive structures adopted by the dinucleotide were grouped according to these distances. For each structure or group of structures (in which structures interconverted rapidly), protection percentages were established for each exchangeable hydrogen. These protection percentages were defined as the time percentages (with regard to the "life" time of the structure) during which exchangeable hydrogens interacted with heteroatoms. The hydrogens were considered to be interacting when the distance between it and the heteroatom was between 1.5 and $4.5 \AA$. The previously mentioned concept
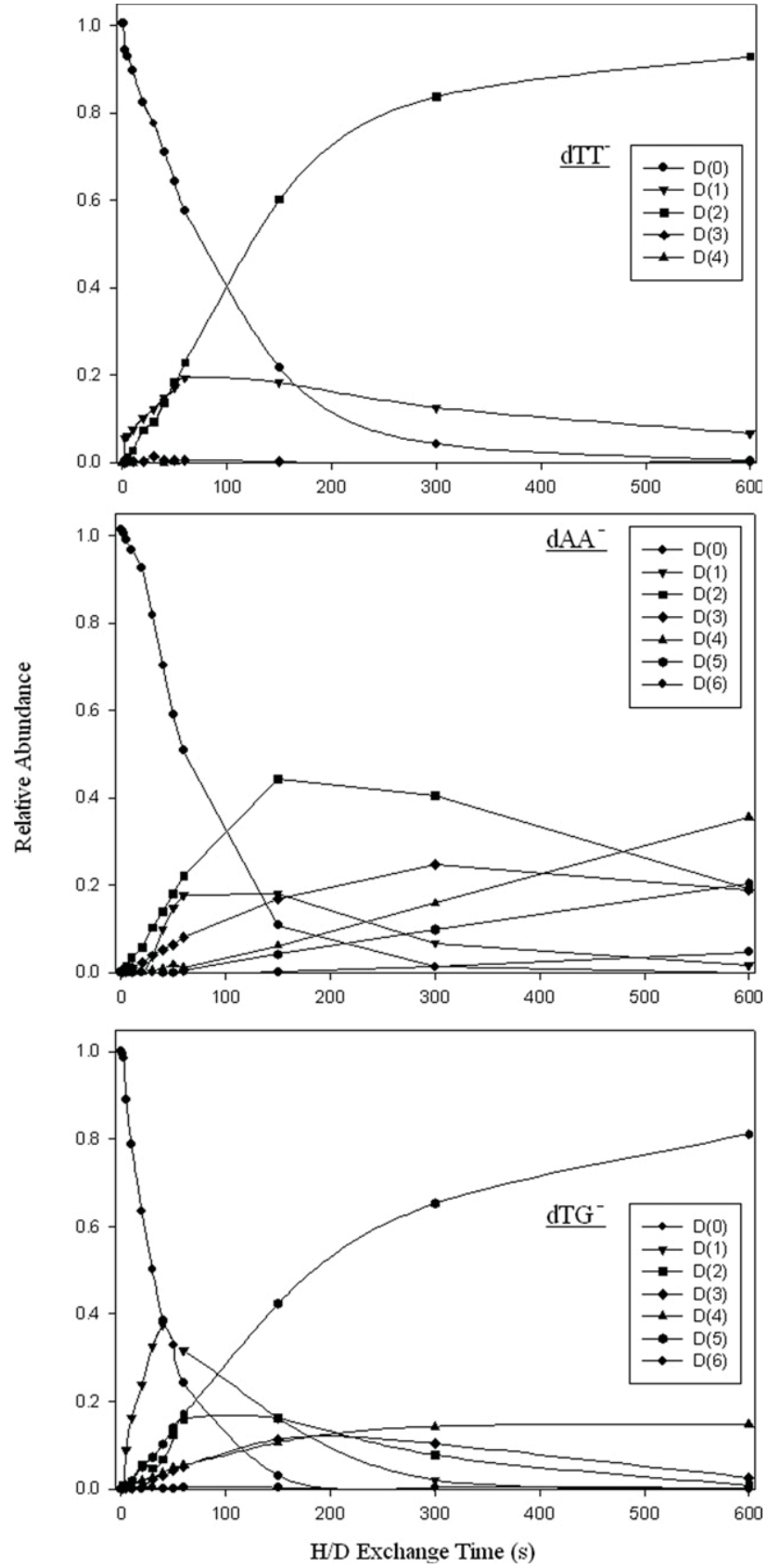

Figure 2. Kinetic plots of the H/D exchange reaction of deprotonated dTT, dAA, and dTG.

of protection follows from the electrostatic approach. It illustrates the fact that when a hydrogen is involved in an interaction, it is blocked in a particular geometry for a given time during which it is made energetically nonexchangeable. For some hydrogen atoms, the protection extent was also estimated by the time percentage during which these atoms were protected in a cavity. This corresponds to a group of atoms that, surrounding a hydrogen, make it sterically inaccessible for H/D exchange. The distinctive structures and the protection extents are summarized for all of the six deprotonated dinucleotides ${ }^{\circ}{ }^{\circ}{ }^{\circ}$ Table $^{\circ} 2 .^{\circ} \mathrm{A}^{\circ}$ closed $^{\circ}$ structure, ${ }^{\circ}$ unlike ${ }^{\circ}$ an 
Table 1. Summary of underlined features for all of the six deprotonated dinucleotides

\begin{tabular}{|c|c|c|c|c|}
\hline \multirow{2}{*}{$\begin{array}{l}\text { The } \\
\text { deprotonated } \\
\text { dinucleotide }\end{array}$} & \multirow{2}{*}{$\begin{array}{l}\text { The number of } \\
\text { exchangeable } \\
\text { hydrogens }\end{array}$} & \multirow{2}{*}{$\begin{array}{l}\text { The number of } \\
\text { exchanged } \\
\text { hydrogens } \\
\text { after } 600 \mathrm{~s} \text { of } \\
\text { reaction }\end{array}$} & \multicolumn{2}{|c|}{ Features } \\
\hline & & & Major species at given reaction times & Kinetic progression \\
\hline $\mathrm{dTT}^{-}$ & 4 & 2 & $\mathbf{D}(2)$ was always the major species & \multirow{3}{*}{$\begin{array}{l}\text { A non-ordinary kinetic behavior } \\
\text { was observed. } D(2) \text { appeared } \\
\text { at the same time that } D(1) \text {. } \\
\text { The H/D exchange kinetics } \\
\text { seemed to be non-consecutive }\end{array}$} \\
\hline $\mathrm{dAT}^{-}$ & 5 & 2 & $\mathrm{D}(2)$ was always the major species & \\
\hline $\mathrm{dAA}^{-}$ & 6 & 6 & $\begin{array}{l}\text { D(2) was the major species until } 475 \mathrm{~s} \\
\text { of reaction }\end{array}$ & \\
\hline $\mathrm{dTG}^{-}$ & 6 & 5 & $\begin{array}{l}\mathbf{D}(\mathbf{1}) \text { was the major species from } 0 \text { to } \\
90 \mathrm{~s} \text { and } \mathbf{D}(\mathbf{5}) \text { became the major } \\
\text { species after } 90 \mathrm{~s} \text { of reaction }\end{array}$ & \multirow{3}{*}{$\begin{array}{l}\text { A fast increase of species with a } \\
\text { large number of exchanged } \\
\text { hydrogens was observed }\end{array}$} \\
\hline $\mathrm{dAG}^{-}$ & 7 & 7 & $\begin{array}{l}\mathbf{D}(1) \text { was the major species from } 0 \text { to } \\
150 \mathrm{~s} \text { of reaction, } \mathbf{D ( 5 )} \text { was the } \\
\text { major species from } 150 \mathrm{~s} \text { to } 360 \mathrm{~s}\end{array}$ & \\
\hline $\mathrm{dGG}^{-}$ & 8 & 8 & $\begin{array}{l}D(1), D(2) \text { and } D(3) \text { were the major } \\
\text { species at first reaction times. } D(8) \\
\text { became the major species after } \\
200 \mathrm{~s} \text { of reaction }\end{array}$ & \\
\hline
\end{tabular}

Table 2. Summary of the distinctive structures and of the protection extents for all of the six deprotonated dinucleotides

\begin{tabular}{|c|c|c|c|c|}
\hline \multirow{2}{*}{$\begin{array}{l}\text { The deprotonated } \\
\text { dinucleotide }\end{array}$} & \multirow[b]{2}{*}{ The distinctive structures } & \multirow{2}{*}{$\begin{array}{l}\text { The life time in } \\
\text { percentage of } \\
\text { the structure }\end{array}$} & \multicolumn{2}{|c|}{$\begin{array}{c}\text { The protection extent of each labile } \\
\text { hydrogen }\end{array}$} \\
\hline & & & $5^{\prime}$ & $3^{\prime}$ \\
\hline \multirow[t]{4}{*}{$\mathrm{dTT}^{-}$} & The open structure & $10.9 \%$ & $\mathrm{OH}: 0 \%$ & $\mathrm{OH}: 0 \%$ \\
\hline & & & $\mathrm{NH}: 0 \%$ & $\mathrm{NH}: 0 \%$ \\
\hline & The closed structure & $90.1 \%$ & $\mathrm{OH}: 0 \%$ & $\mathrm{OH}: 0 \%$ \\
\hline & & & $\mathrm{NH}: 85 \%$ & $\mathrm{NH}: 87 \%$ \\
\hline \multirow[t]{4}{*}{$d A T^{-}$} & The open structure & $14.9 \%$ & $\mathrm{OH}: 0 \%$ & $\mathrm{OH}: 0 \%$ \\
\hline & & & $\mathrm{NH} 2: 0 \%-0 \%$ & $\mathrm{NH}: 0 \%$ \\
\hline & The closed structure & $85.1 \%$ & $\mathrm{OH}: 0 \%$ & $\mathrm{OH}: 0 \%$ \\
\hline & & & NH2: $76 \%-78 \%$ & $\mathrm{NH}: 75 \%$ \\
\hline \multirow[t]{4}{*}{$\mathrm{dAA}^{-}$} & The open structure & $2.3 \%$ & $\mathrm{OH}: 0 \%$ & $\mathrm{OH}: 0 \%$ \\
\hline & & & $\mathrm{NH} 2: 0 \%-0 \%$ & NH2: $0 \%-0 \%$ \\
\hline & The group of closed structures & $97.7 \%$ & $\mathrm{OH}: \sim 30 \%$ & $\mathrm{OH}: 0 \%$ \\
\hline & & & NH2: $53 \%-52 \%$ & NH2: $69 \%-68 \%$ \\
\hline \multirow[t]{6}{*}{$\mathrm{dTG}^{-}$} & The closed Structure A & $50 \%$ & $\mathrm{OH}: 0 \%$ & $\mathrm{OH}: 0 \%$ \\
\hline & & & $\mathrm{NH}: 0 \%$ & $\mathrm{NH}: 0 \%$ \\
\hline & & & & NH2: $100 \%-0 \%$ \\
\hline & The closed Structure B & $50 \%$ & $\mathrm{OH}: 54 \%$ & $\mathrm{OH}: 0 \%$ \\
\hline & & & $\mathrm{NH}: 65 \%$ & $\mathrm{NH}: 64 \%$ \\
\hline & & & & NH2: $100 \%-62 \%$ \\
\hline \multirow[t]{3}{*}{$\mathrm{dAG}^{-}$} & The group of closed structures & $100 \%$ & $\mathrm{OH}: \sim 25 \%$ & $\mathrm{OH}: 0 \%$ \\
\hline & & & NH2: $69 \%-70 \%$ & $\mathrm{NH}: 50 \%$ \\
\hline & & & & NH2: $65 \%-35 \%$ \\
\hline \multirow[t]{6}{*}{$\mathrm{dGG}^{-}$} & The closed structure with $3^{\prime} \mathrm{G}$ & $50 \%$ & $\mathrm{OH}: 0 \%$ & $\mathrm{OH}: 0 \%$ \\
\hline & in syn orientation & & NH: $75 \%$ & $\mathrm{NH}: 0 \%$ \\
\hline & & & NH2: $94 \%-94 \%$ & NH2: $10 \%-90 \%$ \\
\hline & The closed structure with $3^{\prime} \mathrm{G}$ & $50 \%$ & $\mathrm{OH}: 100 \%$ & $\mathrm{OH}: 0 \%$ \\
\hline & in anti orientation & & $\mathrm{NH}: 75 \%$ & $\mathrm{NH}: 96 \%$ \\
\hline & & & NH2: $49 \%-45 \%$ & NH2: $92 \%-\sim 25 \%$ \\
\hline
\end{tabular}



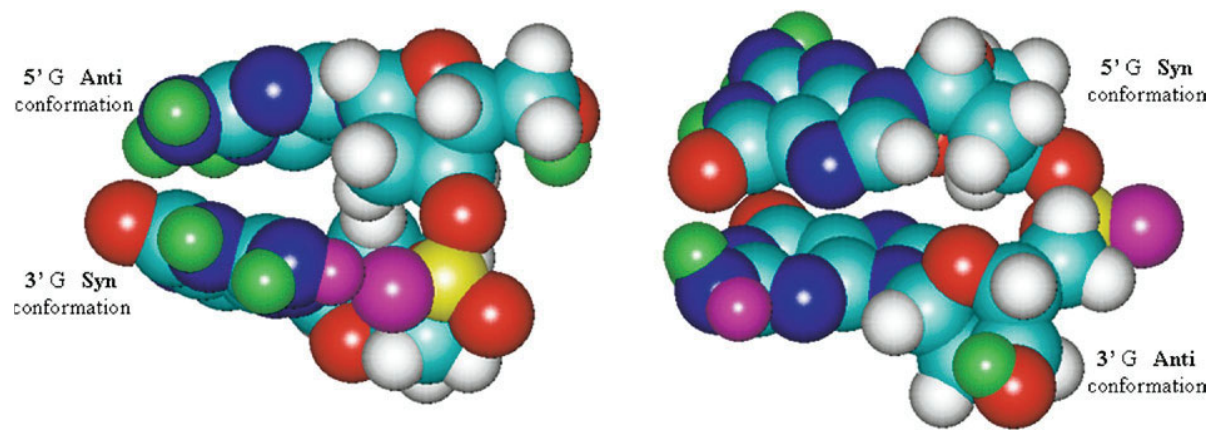

Figure 3. The distinctive structures of $\mathrm{dGG}^{-}$. On the left structure, the $3^{\prime}$ nucleobase is in the syn orientation. One hydrogen from the $\mathrm{NH}_{2}$ group of this nucleobase interacts with an oxygen of the phosphate group (the interacting atoms are painted in purple). On the right structure, the $3^{\prime}$ nucleobase is in the anti orientation and the previously mentioned interaction is not present. The exchangeable hydrogens are painted in green.

open structure, corresponds to a structure where the two nucleobases are one above the other; a hydrogen of one nucleobase being able to interact with a heteroatom of the other nucleobase. In $\mathrm{dTG}^{-}$and $\mathrm{dAG}^{-}$, the base $\mathrm{G}$ was always in the syn orientation. Because of this syn orientation, one hydrogen from the $\mathrm{NH}_{2}$ group of the base $G$ interacted with an oxygen of the phosphate group ${ }^{\circ}\left[6,{ }^{\circ} 20^{\circ}-23\right]^{\circ} .^{\circ}$ or $^{\circ} \mathrm{dTG}^{-},{ }^{\circ}$ the ${ }^{\circ}$ interacting ${ }^{\circ}$ hydrogen was the same during the molecular dynamics calculations. For $\mathrm{dAG}^{-}$, the interacting hydrogen changed once during the molecular modeling. This could explain the stopped $\mathrm{H} / \mathrm{D}$ exchange to $\mathrm{D}(5)$ for $\mathrm{dTG}^{-}$and the complete exchange for $\mathrm{dAG}^{-}$. As $\mathrm{dAG}^{-}$was observed as a group of rapidly interconverted structures, these conformations were analyzed in more detail. In each of these structures, two hydrogens (not necessary the same ones) were more protected. This could explain that $\mathrm{D}(5)$ was the major species from 150 to $360 \mathrm{~s}$ of exchange. ${ }^{\circ}$ Taking $^{\circ}$ into $^{\circ}$ account $^{\circ}$ data $^{\circ}$ in $^{\circ}$ Table $^{\circ} 2^{\circ}$ and according to the previous analysis, the vast majority of the ${ }^{\circ}$ observed ${ }^{\circ}$ features ${ }^{\circ}\left(\text { Table }^{\circ} 1\right)^{\circ}$ were ${ }^{\circ}$ justified. ${ }^{\circ}$ To $^{\circ}$ confirm the major influence of the hydrogen accessibility on H/D exchange and to explain the observed nonconsecutive reaction kinetics, kinetic plots were simulated from the protection extents.

In $\mathrm{dGG}^{-}$, the $3^{\prime}$ base was in the syn orientation (one hydrogen from the $\mathrm{NH}_{2}$ group interacts with an oxygen of the phosphate group) for one molecular dynamics calculation and in the anti orientation (the previously mentioned interaction is not present) for the second molecular modeling $^{\circ}\left(\right.$ Figure $\left.^{\circ} 3\right) .{ }^{\circ}$ To $^{\circ}$ compare $^{\circ}$ this ${ }^{\circ}$ different $^{\circ}$ behavior

Table 3. The energy difference between the anti and syn orientations $(\mathrm{kcal} / \mathrm{mol})$

\begin{tabular}{cccc}
\hline $\begin{array}{c}\text { The deprotonated } \\
\text { dinucleotide }\end{array}$ & $\begin{array}{c}\text { RHF/6-31G- } \\
\text { aug }\end{array}$ & $\begin{array}{c}\text { B3LYP/6-31G- } \\
\text { aug }\end{array}$ & $\begin{array}{c}\text { RHF/6-31*G- } \\
\text { aug }\end{array}$ \\
\hline \hline dTG $^{-}$ & 5.2256 & 6.4934 & 4.7621 \\
dAG $^{-}$ & 7.5325 & 11.3691 & 8.1387 \\
dGG $^{-}$ & 0.8655 & 0.3710 & 0.2215 \\
\hline
\end{tabular}

The syn orientation is lower in energy. with respect to $\mathrm{dTG}^{-}$and $\mathrm{dAG}^{-}$, ab initio geometry optimizations for the syn and anti conformations of the $3^{\prime}$ nucleobase $\mathrm{G}$ were performed with Gaussian 03 for these three deprotonated dinucleotides. The obtained energies at different levels of theory and with different basis sets are $^{\circ}$ presented $^{\circ}$ in $^{\circ}$ Table $^{\circ} 3 .^{\circ}$ For $^{\circ}$ each $^{\circ}$ conformation, ${ }^{\circ}$ all starting points resulted in identical local minimum. For $\mathrm{dTG}^{-}$and $\mathrm{dAG}^{-}$the more stable orientation of the $3^{\prime}$ nucleobase $\mathrm{G}$ is the syn orientation. For $\mathrm{dGG}^{-}$the syn and anti orientations seem to have the same energy and so the same probability.

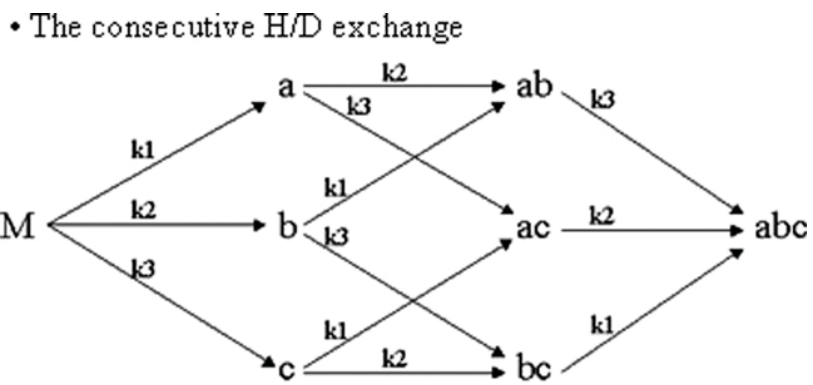

- The simultaneous H/D exchange

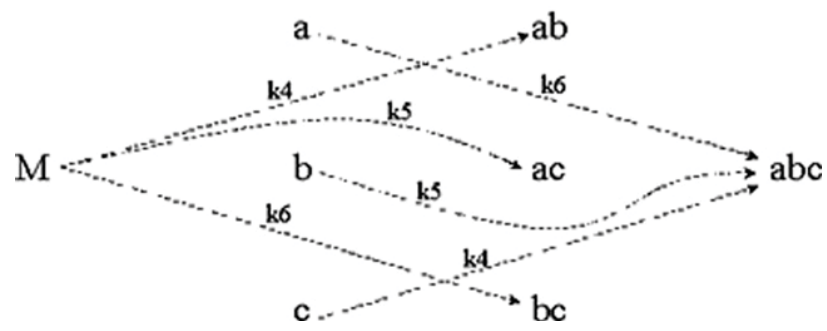

Figure 4. Illustration of the proposed kinetic mechanism that consists of consecutive and simultaneous H/D exchange reactions. $\mathrm{M}$ is the non-deuterated ion, $\mathrm{a}, \mathrm{b}, \mathrm{c}$ correspond to the three exchangeable hydrogens and k1, k2, and k3 are their rate constants. 
Table 4. The protection extent and the corresponding rate constant of each exchangeable hydrogen of $\mathrm{dAA}^{-}$(the used set of coupled differential equations corresponds to the five most exchangeable hydrogens)

\begin{tabular}{ccccc}
\hline & $\begin{array}{c}\text { The labile } \\
\text { hydrogens }\end{array}$ & $\begin{array}{c}\text { The protection } \\
\text { extents }\end{array}$ & $\begin{array}{c}\text { The rate } \\
\text { constants }\left(\mathrm{s}^{-1}\right)^{\mathrm{a}}\end{array}$ \\
\hline \hline $5^{\prime}$ & $\mathrm{OH}$ & $30 \%$ & 0.0012 & $\mathrm{~b}$ \\
& $\mathrm{NH}_{2}$ & $53 \%$ & 0.00075 & $\mathrm{c}$ \\
& & $52 \%$ & 0.00075 & $\mathrm{~d}$ \\
& & & & \\
$3^{\prime}$ & $\mathrm{OH}$ & $0 \%$ & 0.002 & $\mathrm{a}$ \\
& $\mathrm{NH}_{2}$ & $69 \%$ & 0.00045 & $\mathrm{e}$ \\
& & $68 \%$ & 0.00045 & \\
\hline
\end{tabular}

${ }^{a} \mathrm{As} \mathrm{CD}_{3} \mathrm{OD}$ is in excess, its concentration can be considered as constant and the reaction as having an apparent first-order kinetics.

\section{Kinetic Simulations}

As mentioned above, the H/D exchange itself was not the limiting step. The $\mathrm{D}(1)$ and $\mathrm{D}(2)$ species appeared at the same rate and species with a large number of exchanged hydrogens appeared rapidly. To explain these observations, a new kinetic mechanism was proposed. It is illustrated for three exchangeable hydrogens with the diagram in ${ }^{\circ}$ Figure ${ }^{\circ}$. $^{\circ}$ This ${ }^{\circ}$ kinetic $^{\circ}$ mechanism ${ }^{\circ}$ indicates ${ }^{\circ}$ that ${ }^{\circ}$ if ${ }^{\circ}$ the number of collisions between deuterated methanol and dinucleotide ions was sufficient and if two hydrogens on the same deprotonated dinucleotide were accessible at the same time, these two hydrogens could be exchanged simultaneously at the experimental time scale. This mechanism was used to reproduce the H/D exchange experimental plots. To build these simulated kinetic plots, each exchangeable hydrogen was given an exchange rate constant according to its protection extent. Moreover, the model was based on the assumption that the rate constant of the simultaneous exchange reaction of two hydrogens corresponded to the rate constant of the slowest. The rate constants that were used for the simulation of $\mathrm{dAA}^{-}$ kinetic ${ }^{\circ}$ plot $^{\circ}$ are $^{\circ}$ given $^{\circ}$ in $^{\circ}$ Tables $^{\circ} 4^{\circ}$ and $^{\circ} 5 .{ }^{\circ}$ The ${ }^{\circ}$ simulated plots $^{\circ}$ of $^{\circ} \mathrm{dTT}^{-\circ}$ and ${ }^{\circ} \mathrm{dAA}^{-}{ }^{\circ}$ are $^{\circ}$ presented ${ }^{\circ}$ in $^{\circ}$ Figure ${ }^{\circ} 5 .{ }^{\circ}$ For $\mathrm{dTG}^{-}$, the experimental plot was approached in adding the kinetic contributions of the two structures. This kinetic

Table 5. The set of rate constants $\left(\mathrm{s}^{-1}\right)^{\mathrm{a}}$ used to simulate the kinetic plot of dAA

\begin{tabular}{ccc}
\hline $\begin{array}{c}\text { The consecutive } H / D \\
\text { exchange }\end{array}$ & $\begin{array}{c}\text { The simultaneous } H / D \\
\text { exchange }\end{array}$ \\
\hline \hline $\mathrm{M}$ & $\mathrm{a}=0.002$ & $\mathrm{ab}=0.0012$ \\
& $\mathrm{ac}=0.00075$ \\
& $\mathrm{ad}=0.00075$ \\
& $\mathrm{a}=0.0012$ & $\mathrm{a}=0.00045$ \\
$\mathrm{c}=0.00075$ & $\mathrm{bc}=0.00075$ \\
& $\mathrm{bd}=0.00075$ \\
& $\mathrm{be}=0.00045$ \\
& $\mathrm{~cd}=0.00075$ & $\mathrm{ce}=0.00075$ \\
& $\mathrm{de}=0.00045$ \\
\hline
\end{tabular}

${ }^{\mathrm{a}} \mathrm{As} \mathrm{CD}_{3} \mathrm{OD}$ is in excess, its concentration can be considered as constant and the reaction as having an apparent first-order kinetics.

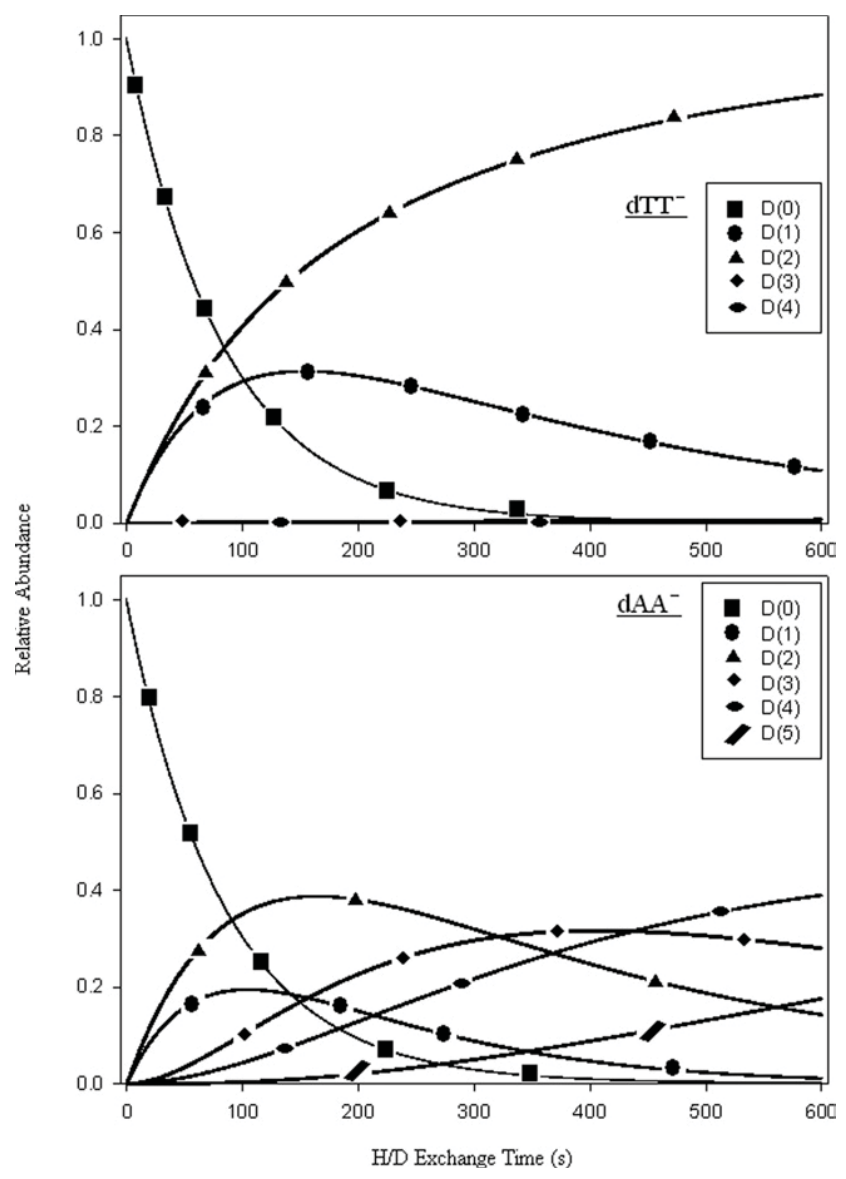

Figure 5. Kinetic simulated plots of $\mathrm{dTT}^{-}$and $\mathrm{dAA}^{-}$using MatLab. For $\mathrm{dTT}^{-}$, the simultaneous exchange probability is twice the consecutive exchange probability. For $\mathrm{dAA}^{-}$, these two probabilities are the same (for $\mathrm{dAA}^{-}$, the used set of coupled differential equations corresponds to the five most exchangeable hydrogens).

mechanism was also applied to previously published mononucleotide ${ }^{\circ} \mathrm{H} / \mathrm{D}^{\circ}$ exchange $[16]^{\circ}{ }^{\circ} \mathrm{A}^{\circ}$ very $^{\circ}$ good ${ }^{\circ}$ agreement with the kinetic plots was obtained. As previously mentioned, the relay mechanism requires the formation of a hydrogen-bonded complex between a hydrogen donor site of the nucleotide, the deuterating agent, and a deuterium acceptor site (the phosphate group) of the nucleotide, involving the restriction of the distance between the hydrogen donor and acceptor sites. The formation of such a three-partner complex is entropically unfavorable. Moreover, for dinucleotides, this relay mechanism is not appropriate as the distances between the hydrogen donor and deuterium acceptor sites are not compatible. A "direct" $\mathrm{H} / \mathrm{D}$ exchange between the deuterating agent and the site bearing the exchangeable hydrogen is more relevant for dinucleotides. This "direct" exchange could be combined with the relay mechanism to explain the mononucleotides H/D exchange. In suitable experimental conditions, the simultaneous exchange should be taken into account for mononucleotides exchange. Possibly, this could be applied to the relay mechanism if it is sufficiently fast in comparison to the experimental time scale. For all 
of the kinetic simulations, the value of the simultaneous exchange probability was either equal to or in the range of up to twice the value of the consecutive exchange probability. The fact that these two probabilities can differ is not excluded and must depend on the H/D exchange experimental conditions. To support the simultaneous exchange of two accessible hydrogens, the number of collisions between a dinucleotide ion and a $\mathrm{CD}_{3} \mathrm{OD}$ gas was estimated. At the experimental pressure and according to [26], ${ }^{\circ}$ the ${ }^{\circ}$ mean $^{\circ}$ free $^{\circ}$ path $^{\circ}$ should $^{\circ}$ be $^{\circ}$ such $^{\circ}$ that ${ }^{\circ}$ the ${ }^{\circ}$ dinucleotide ions undergo at least $10^{4}$ collisions per second.

\section{Conclusions}

Studies have been performed on six dinucleotides with $\mathrm{CD}_{3} \mathrm{OD}$ as the deuterating agent in the second hexapole of an FTICR-MS to assess the ability of H/D exchange to characterize coexisting conformers. In the experimental conditions, H/D exchange has been shown to be controlled by hydrogen accessibility. This hydrogen accessibility is in direct relationship with the biomolecular conformation and can be a function not only of interactions with heteroatoms but also of protection in a cavity. With hydrogen accessibility as the dominant factor, the H/D exchange study of biomolecular structures can be done without taking into account the chemical nature of the heteroatom bearing the hydrogen. This argument will be correct while the H/D exchange reaction is faster than the structure interconversion. Within this framework, a model including simultaneous $\mathrm{H} / \mathrm{D}$ exchanges at the experimental time scale is proposed. This model allows dinucleotide H/D exchange kinetic plots and also mononucleotide H/D exchange kinetic plots to be reproduced. These conclusions are important for the study of the gas-phase conformations of larger biomolecules including noncovalent complexes. With hydrogen accessibility as the main factor for the exchange rates, structural modifications during ligand binding can be studied by direct counting of proton in groups associated with different structures.

\section{Acknowledgments}

The authors acknowledge Jean-François Greisch for the adjustment of the in-house software and Dominique Toye for the programming of Matlab. This work was supported by the FRSFNRS (Fond de la Recherche Scientifique-FNRS, Belgium). DD was supported by the BelSPo Program IAP P6/19.

\section{References}

1. Gard, E.; Green, M. K.; Bregar, J.; Lebrilla, C. B. Gas-Phase Hydrogen/ Deuterium Exchange as a Molecular Probe for the Interaction of Methanol and Protonated Peptides. J. Am. Soc. Mass Spectrom. 1994, 5, 623-631.

2. Campbell, S. C.; Rodgers, M. T.; Marzluff, E. M.; Beauchamp, J. L. Deuterium Exchange Reactions as a Probe of Biomolecule Structure. Fundamental Studies of Gas Phase H/D Exchange Reactions of Protonated Glycine Oligomers with $\mathrm{D}_{2} \mathrm{O}, \mathrm{CD}_{3} \mathrm{OD}, \mathrm{CD}_{3} \mathrm{CO}_{2} \mathrm{D}$, and $\mathrm{ND}_{3}$. J. Am. Chem. Soc. 1995, 117, 12840-12854.

3. Freitas, M. A.; Shi, S. D. H.; Hendrickson, C. L.; Marshall, A. G. Gas-Phase RNA and DNA Ions. 1. H/D Exchange of the $[\mathrm{M}-\mathrm{H}]^{-}$Anions of Nucleoside 5' Monophosphates (GMP, dGMP, AMP, dAMP, CMP, dCMP, UMP, dTMP), Ribose 5-Monophosphate, and 2-Deoxyribose
5-Monophosphate with $\mathrm{D}_{2} \mathrm{O}$ and $\mathrm{D}_{2}$ S. J. Am. Chem. Soc. 1998, 120, 10187-10193.

4. Robinson, J. M.; Greig, M. J.; Griffey, R. H.; Venkantraman, M.; Laude, D. A. Hydrogen/Deuterium Exchange of Nucleotides in the Gas Phase. Anal. Chem. 1998, 70, 3566-3571.

5. Freitas, M. A.; Marshall, A. G. Gas-Phase RNA and DNA Ions. 2. Conformational Dependence of the Gas-Phase H/D Exchange of Nucleotide 5' Monophosphates. J. Am. Soc. Mass Spectrom. 2001, 12, $780-785$.

6. Wyttenbach, T.; Bowers, M. T. The Hydrogen/Deuterium Exchange Mechanism. J. Am. Soc. Mass Spectrom. 1999, 10, 9-14.

7. Gree-Church, K. B.; Limbach, P. A.; Freitas, M. A.; Marshall, A. G. Gas-Phase Hydrogen/Deuterium Exchange of Positively Charged Mononucleotides by Use of Fourier-Transform Ion Cyclotron Resonance Mass Spectrometry. J. Am. Soc. Mass Spectrom. 2001, 12, 268-277.

8. Crestoni, M. E.; Fornarini, S. Gas-Phase Hydrogen/Deuterium Exchange of Adenine Nucleotides. J. Mass Spectrom. 2003, 38, 854-861.

9. Wang, F.; Freitas, M. A.; Marshall, A. G.; Skyes, B. D. Gas-Phase Memory of Solution-Phase Protein Conformation: H/D Exchange and Fourier Transform Ion Cyclotron Resonance Mass Spectrometry of the N-Terminal Domain of Cardiac Troponin C. Int. J. Mass Spectrom. 1999, 192, 319-325.

10. Herrmann, K.; Wysocki, V.; Vorpagel, E. R. Computational Investigation and Hydrogen/Deuterium Exchange of the Fixed Charge Derivative Tris(2,4,6-Trimethoxyphenyl) Phosphonium: Implication of the Aspartic Acid Cleavage Mechanism. J. Am. Soc. Mass Spectrom. 2005, 16 , 1067-1080.

11. Herrmann, K. A.; Kuppannan, K.; Wysocki, V. H. Fragmentation of Doubly-Protonated Peptide Ion Populations Labeled by H/D Exchange with $\mathrm{CD}_{3} \mathrm{OD}$. Int. J. Mass Spectrom. 2006, 249/250, 93-105.

12. Reid, G. E.; Simpson, R. J.; O'Hair, R. A. J. Probing the Fragmentation Reactions of Protonated Glycine Oligomers Via Multistage Mass Spectrometry and Gas Phase Ion-Molecule Hydrogen/Deuterium Exchange. Int. J. Mass Spectrom. 1999, 191, 209-230.

13. Felix, T.; Reyzer, M.; Brodbelt, J. Hydrogen/Deuterium Exchange of Nucleoside Analogs in a Quadrupole Ion Trap Mass Spectrometer. Int. J. Mass Spectrom. 1999, 191, 161-170.

14. Reyzer, M. L.; Brodbelt, J. S. Gas-Phase H/D Exchange Reactions of Polyamine Complexes: $(\mathrm{M}+\mathrm{H})^{+},\left(\mathrm{M}+\right.$ Alkali Metal $\left.^{+}\right)$, and $(\mathrm{M}+$ $2 \mathrm{H})^{2+}$. J. Am. Soc. Mass Spectrom. 2000, 11, 711-721.

15. Zhang, J.; Brodbelt, J. S. Gas-Phase Hydrogen/Deuterium Exchange and Conformations of Deprotonated Flavonoids and Gas-Phase Acidities of Flavonoids. J. Am. Chem. Soc. 2004, 126, 5906-5919.

16. Chipuk, J. E.; Brodbelt, J. S. Gas-Phase Hydrogen/Deuterium Exchange of $5^{\prime}$ and $3^{\prime}$ Mononucleotides in a Quadrupole ion Trap: Exploring the Role of Conformation and System Energy. J. Am. Soc. Mass Spectrom. 2007, 18, 724-736.

17. Gidden, J.; Bowers, M. T. Gas-Phase Conformational and Energetic Properties of Deprotonated Dinucleotides. Eur. Phys. J. D 2002, 20, 409-419.

18. Goodner, K. L.; Milgram, K. E.; Williams, K. R.; Watson, C. H.; Eyler, J. R. Quantification of Ion Abundances in Fourier Transform Ion Cyclotron Resonance Mass Spectrometry. J. Am. Soc. Mass Spectrom. 1998, 9, 1204-1212.

19. Marshall, A. G.; Comisarow, M. B.; Parisod, G. Relaxation and Spectral Line Shape in Fourier Transform Ion Resonance Spectroscopy. J. Chem. Phys. 1979, 71, 4434-4444.

20. Nir, E.; Imhof, P.; Kleinermanns, K.; de Vries, M. S. REMPI Spectroscopy of Laser Desorbed Guanosines. I. Am. Chem. Soc. 2000, 122, 8091-8092.

21. Rodgers, M. T.; Campbell, S.; Marzluff, E. M.; Beauchamp, J. L. Low-Energy Collision-Induced Dissociation of Deprotonated Dinucleotides: Determination of the Energetically Favored Dissociation Pathways and the Relative Acidities of Nucleic Acid Bases. Int. J. Mass Spectrom. Ion Processes 1994, 137, 121-149.

22. Gidden, J.; Bowers, M. T. Gas-Phase Conformation of Deprotonated and Protonated Mononucleotides Determined by Ion Mobility and Theoretical Modeling. J. Phys. Chem. 2003, 107, 12829-12837.

23. Liu, D.; Wyttenbach, T.; Bowers, M. T. Hydration of Mononucleotides. J. Am. Chem. Soc. 2006, 128, 15155-15163.

24. Saenger, W. Principles of Nucleic Acid Structure; Springer-Verlag: New York, 1984. pp. 14-23.

25. Frisch, M. J.; Trucks, G. W.; Schlegel, H. B.; Scuseria, G. E.; Robb, M. A.; Cheeseman, J. R.; Montgomery, J. A., Jr.; Vreven, T.; Kudin, K. N.; Burant, J. C.; Millam, J. M.; Iyengar, S. S.; Tomasi, J.; Barone, V.; Mennucci, B.; Cossi, M.; Scalmani, G.; Rega, N.; Petersson, G. A.; Nakatsuji, H.; Hada, M.; Ehara, M.; Toyota, K.; Fukuda, R.; Hasegawa, J.; Ishida, M.; Nakajima, T.; Honda, Y.; Kitao, O.; Nakai, H.; Klene, M.; Li, X.; Knox, J. E.; Hratchian, H. P.; Cross, J. B.; Adamo, C.; Jaramillo, J.; Gomperts, R.; Stratmann, R. E.; Yazyev, O.; Austin, A. J.; Cammi, R.; Pomelli, C.; Ochterski, J. W.; Ayala, P. Y.; Morokuma, K.; Voth, G. A.; Salvador, P.; Dannenberg, J. J.; Zakrzewski, V. G.; Dapprich, S.; Daniels, A. D.; Strain, M. C.; Farkas, O.; Malick, D. K.; Rabuck, A. D.; Raghavachari, K.; Foresman, J. B.; Ortiz, J. V.; Cui, Q.; Baboul, A. G.; Clifford, S.; Cioslowski, J.; Stefanov, B. B.; Liu, G.; Liashenko, A.; Piskorz, P. Komaromi, I.; Martin, R. L.; Fox, D. J.; Keith, T.; Al-Laham, M. A.; Peng, C. Y.; Nanayakkara, A.; Challacombe, M.; Gill, P. M. W.; Johnson, B.; Chen, W.; Wong, M. W.; Gonzalez, C.; Pople, J. A. Gaussian 03, Revision C. 02; Gaussian, Inc.: Wallingford, CT, 2004.

26. McDonnell, L. A.; Giannakopulos, A. E.; Derrick, P. J.; Tsybin, Y. O. Hakansson, P.A. Theoretical Investigation of The Kinetic Energy of Ions Trapped in a Radio-Frequency Hexapole Ion Trap. Eur. J. Mass Spectrom. 2002, 8, 181-189. 